\title{
Preventive sublingual immunotherapy with House Dust Mite extract modulates epitope diversity in pre-school children
}

Ponce, Marta; Schroeder, Fabian; Bannert, Christina; Schmidthaler, Klara; Hansen, Christian Skjødt; Bøgh, Katrine Lindholm; Soldo, Regina; Tsui, Stephen Kwok-Wing; Weinhäusel, Andreas; Szépfalusi, Zsolt

Total number of authors:

11

Published in:

Allergy

Link to article, DOI:

10.1111/all.13658

Publication date:

2019

Document Version

Peer reviewed version

Link back to DTU Orbit

Citation $(A P A)$ :

Ponce, M., Schroeder, F., Bannert, C., Schmidthaler, K., Hansen, C. S., Bøgh, K. L., Soldo, R., Tsui, S. K-W. Weinhäusel, A., Szépfalusi, Z., \& Eiwegger, T. (2019). Preventive sublingual immunotherapy with House Dust Mite extract modulates epitope diversity in pre-school children. Allergy, 74(4), 780-787. https://doi.org/10.1111/all.13658

\section{General rights}

Copyright and moral rights for the publications made accessible in the public portal are retained by the authors and/or other copyright owners and it is a condition of accessing publications that users recognise and abide by the legal requirements associated with these rights.

- Users may download and print one copy of any publication from the public portal for the purpose of private study or research.

- You may not further distribute the material or use it for any profit-making activity or commercial gain

- You may freely distribute the URL identifying the publication in the public portal 
MRS. MARTA PONCE (Orcid ID : 0000-0002-8730-5987)

DR. THOMAS EIWEGGER (Orcid ID : 0000-0002-2914-7829)

Article type : Original Article: Experimental Allergy and Immunology

Preventive sublingual immunotherapy with House Dust Mite extract modulates epitope diversity in pre-school children

Short title: pAIT with HDM extract modulates epitope diversity

Marta Ponce $^{1}$, Fabian Schroeder ${ }^{2}$, Christina Bannert ${ }^{1}$, Klara Schmidthaler ${ }^{1}$, Christian Skjødt Hansen $^{3}$, Katrine Lindholm Bøgh ${ }^{4}$, Regina Soldo ${ }^{2}$, Stephen Kwok-Wing Tsui ${ }^{5,6}$, Andreas Weinhäusel $^{2}$, Zsolt Szépfalusi $^{1 \#}$, Thomas Eiwegger ${ }^{7,8,9 \# *}$

\section{Affiliations:}

${ }^{1}$ Department of Paediatrics and Adolescent Medicine, Medical University of Vienna, Vienna, Austria.

${ }^{2}$ Competence Unit for Molecular Diagnostics - AIT, Austrian Institute of Technology, Vienna, Austria.

${ }^{3}$ Evaxion Biotech, Copenhagen, Denmark.

${ }^{4}$ National Food Institute, Technical University of Denmark, Kgs. Lyngby, Denmark.

This article has been accepted for publication and undergone full peer review but has not been through the copyediting, typesetting, pagination and proofreading process, which may lead to differences between this version and the Version of Record. Please cite this article as doi: $10.1111 /$ all.13658

This article is protected by copyright. All rights reserved. 
${ }^{5}$ Hong Kong Bioinformatics Centre, Chinese University of Hong Kong, Hong Kong, China

${ }^{6}$ School of Biomedical Sciences, Chinese University of Hong Kong, Hong Kong, China.

${ }^{7}$ Program in Translational Medicine, The Hospital for Sick Children, Toronto, Canada

${ }^{8}$ Department of Immunology, The University of Toronto, Toronto, Canada

${ }^{9}$ Division of Immunology and Allergy, Food allergy and Anaphylaxis Program, The Department of Paediatrics, The Hospital for Sick Children, Toronto, Canada

\# contributed equally

\section{Correspondence:}

*Thomas Eiwegger, MD, Division of Immunology and Allergy, Food allergy and Anaphylaxis Program, The Department of Paediatrics, Hospital for Sick Children, Toronto, Canada. University Ave 555 Toronto, Canada, E-mail: thomas.eiwegger@ sickkids.ca, Tel.: + $1416-813-76541862$

Funding: This work was supported by the Austrian Science Fund (FWF) SFB F4615; FWF Doctoral Program W 1248-B13 MCCA and Sickkids start-up funds Thomas Eiwegger, HSBC Bank Canada Catalyst Research Grant from The Hospital for Sick Children.

Author contributions: M.P. took care of the sample preparation, selection of patients according to inclusion criteria, contributed to the design of the arrays, selection of allergens, analysis of data and interpretation of the results and writing of the manuscript. F.S. processed the experimental data and did statistical analysis and R.S. contributed to prepare the samples, 
IgG purification and subsequent quantification, to the processing of the experimental data and contributed to the methods section of the manuscript. K.S. contributed to sample collection and preparation and selection of patients according to inclusion criteria. K. L.B. and C.S.H. helped in the design and analysis and interpretation of the peptide chip. C.B. was involved in the clinical trial and provided the clinical data Z.S. as PI served responsible for design, conduction of the clinical trial, provided the samples. A.W. contributed to the design of the study, design of arrays, analysis of data and interpretation of the results. S.W. provided the draft genome of Dermatophagoides farinae. T.E. and Z.S. conceived the present idea and T.E. designed the study, contributed to manuscript's generation and was involved in data analysis and supervised the whole project.

\begin{abstract}
Background: The preventive effect of allergen immunotherapy (AIT) on allergy and asthma development is currently assessed using primary and secondary AIT approaches. Knowledge of the immunological effects of these interventions is limited and the impact on epitope diversity remains to be defined.
\end{abstract}

Methods: We used high-density peptide arrays that included all known Dermatophagoides pteronyssinus (Der p) and Dermatophagoides farinae (Der f) allergens and the whole proteome of Der f to study changes in House Dust Mite (HDM) linear peptide recognition during a 2-year preventive double-blind placebo-controlled sublingual HDM AIT pilot study in 2-5-year-old children with sensitization to HDM but without symptoms.

Results: Preventive AIT-treated patients showed significantly higher IgG epitope diversity to HDM allergens compared to placebo-treated individuals at 24 months of treatment $(\mathrm{p}<0.05)$, 
while no increase in $\operatorname{IgE}$ diversity was seen. At 24 months of treatment, IgG4 diversity for HDM allergens was significantly higher in the pAIT-treated patients compared to placebo group $(\mathrm{p}<0.05)$. Potentially beneficial changes in epitope recognition throughout the treatment are also seen in peptides derived from Der f proteome.

Conclusions: These data suggest a beneficial immunomodulation of preventive sublingual immunotherapy at a molecular level by favoring a broader blocking repertoire and inhibiting epitope spreading.

Key words: AIT, HDM allergy, linear epitopes, peptide array, preventive.

\section{INTRODUCTION}

Allergen immunotherapy (AIT) is the only causative therapeutic strategy available and has been proven to reduce symptoms and medication scores (1). In analogy to promising primary $(2,3)$ and secondary (4) preventive approaches in food allergy, a few studies tried to implement a preventive AIT (pAIT) approach for sublingual AIT to environmental allergens, such as House Dust Mite (HDM) (5-7). HDM is the most important perennial allergen and is highly associated with asthma development (8). Preventive AIT is of special interest since prospective and retrospective analysis of AIT studies suggested an impact on the atopic march (9-11). A recent meta-analysis suggested a significant short-term reduction of asthma development in patients with allergic rhinitis treated with AIT (12). Two placebo-controlled trials were performed to assess prevention of onset of allergy with sublingual AIT $(6,7)$. The first trial focused on safety, feasibility and immunological modulation. It demonstrated that pAIT in 2-5-year-old children is safe. It also reported the induction of regulatory mechanisms such as an increase of allergen-specific IgG and the suppression of allergen-specific T-cell 
proliferation in an IL-10- and TGF- $\beta$-dependent manner. The second, larger study assessed the benefit of a 12-month HDM pAIT in high-risk, non-sensitized children starting in the first year of life. Although the trial was not able to demonstrate a reduction in the number of HDM sensitizations or HDM allergy, there was a significant reduction of sensitization to allergens other than HDM in the treatment group.

Allergic asthma often occurs at the end of a sequence of events called the atopic march, which is the result of an immunological dysregulation favoring Th2 responses early in life. It is characterized by progressive sensitization to multiple allergens and an increased $\operatorname{IgE}$ epitope diversity over time. It remains to be clarified whether early interventions such as pAIT interfere with allergy development at a molecular level by suppressing epitope spreading (13).

This study takes advantage of a prospective placebo-controlled pAIT trial and focuses on how pAIT affects epitope spreading and the diversity of blocking antibodies by applying novel high-resolution peptide arrays that allow us to investigate the complete linear epitope spectrum of Der $\mathrm{p}$ and Der $\mathrm{f}$.

\section{METHODS}

\section{High-density peptide arrays}

In an initial experimental approach, a 1-million, high-resolution, high-density peptide array was conducted, which screened for IgG, IgG4 and IgE-binding peptides derived from the whole Der $\mathrm{f}$ proteome and from all published Der $\mathrm{p}$ and Der $\mathrm{f}$ allergens. Thus, the peptide array consisted of 13,861 15 amino acid overlapping 16-mer (1-amino-acid resolution) peptides covering the primary sequence of the described allergens of Der $p$ and Der $f$ (WHO/IUIS Allergen Nomenclature Sub-Committee) and 811,007 9 amino acid overlapping 
16-mer peptides (7-amino-acid resolution) covering the primary sequence of Der $\mathrm{f}$ proteome (based on the recently published genome (without the allergen peptides) (14)). Each peptide of the allergen library was synthesized on six randomly distributed spots per array. Peptides from the whole Der f proteome were spotted a single time. Serving as negative control peptides, the library included 38,423 peptides from HDM-unrelated proteins, specifically 148 snake venom toxins (15). From previously-conducted peptide microarray experiments, 437 peptides were selected as positive controls and were randomly distributed on the array in 10 replicates. Peptide synthesis was performed as described previously (16) by in-situ photolithographic synthesis in a Roche-NimbleGen Maskless Array Synthesizer using an amino-functionalized substrate carrying a photosensitive protection group. The total number of peptides on the screening array - denoted 1M array - was 947,425. Plasma from 3 groups: HDM-non-sensitized/non-allergic, HDM-sensitized/non-allergic and HDM-allergic children, was used to pre-select for IgG, IgG4 and IgE-binding peptides.

Based on the binding characteristics of the initial experiment, the second high-density peptide array (also referred as $172 \mathrm{k}$ peptide array in the following sections) with 54,785 unique peptides from the Der f proteome, 1509 unique peptides from already described Der $\mathrm{f}$ and Der $\mathrm{p}$ allergens and 4,493 snake venom toxin peptides (negative control peptides) was designed with all peptides synthesized in duplicates. To investigate dynamics of epitope recognition during pAIT, plasma from 9 pAIT and 10 placebo-treated children were analyzed pre-treatment, at 12 and at 24 months of treatment.

\section{Study population}

As mentioned in the section above, for the initial peptide selection process sera from 3 distinct patient groups were used: HDM-non-sensitized/non-allergic, HDM-sensitized/nonallergic and HDM-allergic children. The group of HDM-non-sensitized/non-allergic 
individuals (mean age $7.2 \pm 4.5$ years) showed no detectable specific IgE levels $(\leq 0.35 \mathrm{kU} / \mathrm{l})$ to a mixture of food and airborne allergens. HDM-sensitized children without clinical symptoms had specific IgE values from 0.9 to $33.9 \mathrm{kU} / \mathrm{l}$ (mean $8.9 \pm 10.0 \mathrm{kU} / \mathrm{l}$ ) to Der $\mathrm{p}$ (mean age $8.9 \pm 6.0$ years). Der p-specific IgE levels were $>100 \mathrm{kU} / \mathrm{l}$ in $8 / 9$ individuals and one patient showed $84.3 \mathrm{kU} / \mathrm{l}$ (mean age $11.2 \pm 4.4$ years) in HDM-allergic group. The majority of HDM-allergic individuals suffered from bronchial asthma and allergic rhinoconjunctivitis related to HDM exposure. Serum was collected at the Vienna General Hospital in the allergy outpatients' ward. Those three clinically different patients group allowed us to define the peptides recognized by clinically different groups.

For the $172 \mathrm{~K}$ array, 9 out of the $11 \mathrm{HDM}$ pAIT-treated and 10 of the 12 placebo-treated children from the preventive sublingual AIT study, all of them sensitized to HDM but without symptoms, were included. Summary of patients' characteristics such as age, gender, allergy family history (defined by known allergies or atopic disease of the parents) are shown in Table 1. The selection was based on the availability of plasma samples from all three visits $(0 \mathrm{~m}$, $12 \mathrm{~m}, 24 \mathrm{~m})$. The study design of an initiated-pAIT trial has been described in detail recently (7).

The immunotherapy extract (NovoHelisen) and placebo were provided by Allergopharma (Rheinbeck, Germany) and contained the following benchmark major allergen concentrations: Der p 1: $9.4 \mu \mathrm{g} / \mathrm{ml}$; Der f 1: $5.7 \mu \mathrm{g} / \mathrm{ml}$. All children were sensitized to HDM (positive Skin Prick Test (SPT) to HDM extract (ALK-Albello) and/or specific IgE to Der p) and 2 to 5 years of age (Table 1). None of them reported any allergen-related symptoms or was on persistent treatment with inhalant steroids for upper and lower airways or topical steroids because of atopic dermatitis. The treatment consisted of drops applied daily under the tongue and divided into two phases: a dose-escalation and a maintenance phase according to the product information (7).

This article is protected by copyright. All rights reserved. 


\section{Sample preparation}

Two types of samples were prepared for the immunoassay: plasma for $\operatorname{IgE}$ and subsequent IgG measurements and purified IgG from the same plasma samples for IgG4 measurements in order to avoid IgE/IgG4 interference.

IgG was purified according to the manufacturer's instruction of the Melon ${ }^{\mathrm{TM}}$ Gel Spin Plate kit for IgG Screening (Thermo Fisher Scientific). IgG concentration of the purified flowthrough was determined by absorbance measures using the Epoch Micro-Volume Spectrophotometer System (BioTek, VT, USA).

Plasma samples were diluted 1:100 in casein binding buffer $(0.01 \mathrm{M}$ Tris-Cl, $\mathrm{pH} 7.4,1 \%$ alkali-soluble casein, $0.05 \%$ Tween-20). The purified IgG samples were diluted 1:16 with Blocker ${ }^{\mathrm{TM}}$ BLOTTO in TBS (Thermo Fisher Scientific), a 5\% solution of non-fat powdered milk in TBS. The diluted samples were incubated on the microarray slides at $4{ }^{\circ} \mathrm{C}$ over night. The arrays were then washed three times in wash buffer (1x TBS, 0.05\% Tween-20), 10 minutes per wash. Goat anti-human IgE antibody, TRITC conjugate (Thermo Fisher Scientific) was used for the IgE detection in the diluted plasma. The antibody was diluted 1:10,000 (final concentration $0.1 \mathrm{ng} / \mu \mathrm{l})$ in secondary binding buffer $(1 \mathrm{x}$ TBS, $1 \%$ alkalisoluble casein, $0.05 \%$ Tween-20). The arrays were incubated for 3 hours at room temperature and then washed 3 times for 10 minutes in wash buffer and 30 seconds in reagent-grade water. Fluorescent signal of the secondary antibody was detected by scanning at $635 \mathrm{~nm}$ for $\operatorname{IgG}$ or $532 \mathrm{~nm}$ for $\mathrm{IgE}$ at a $2 \mu \mathrm{m}$ resolution and $25 \%$ gain, using an MS200 microarray scanner.

Additionally, Alexa Fluor® 647-conjugated goat anti-human IgG (Jackson Immuno Research) was used on the already scanned arrays which were incubated with diluted serum for $\operatorname{IgE}$ detection, in order to investigate the proportion of bound $\operatorname{IgG}$ and $\operatorname{IgE}$ on the same 
array. Furthermore, the already scanned arrays which were screened for bound purified IgG were then incubated with a mouse anti-human IgG4 Fc-Alexa Fluor ${ }^{\circledR} 555$ (Southern Biotech) antibody. In total, 3 different data sets were generated (IgE, IgG, and IgG4). In the IgG4 data set, data from 2 patients of each group had to be excluded since they did not meet the quality control requirements.

For the screening experiment, 3 pools consisting of 3 serum samples per pool for allergic, sensitized non-allergic and non-sensitized, non-allergic individuals were measured (i.e. 3 samples per group harboring immunoglobulin diversity of a total of 9 patients totaling sera from 27 well-characterized individuals).

\section{Data analysis}

Data pre-processing was comparable for the $1 M$ and the $172 \mathrm{~K}$ high-density peptide arrays. A sample-wise standardization of the fluorescence intensity of all analyzed peptide fields by means of negative control peptides originating from snake venom toxins was done. For each sample, the median (m) and the Median Absolute Deviation (MAD), robust estimates of the central location and the spread, were calculated and a signal-to-baseline Z-score was obtained for each HDM peptide signal $(\mathrm{x})$, using $\mathrm{Z}=(\mathrm{x}-\mathrm{m}) / \mathrm{MAD}$. Additionally, peptides from HDMdescribed allergens were normalized with a rolling median with a window size of three (i.e. the median signal of a given peptide and the two adjacent peptides). In this procedure, the peptides were assigned the median of the original signal value and the signal of the two adjacent peptides according to the protein sequence, eliminating singular peptide responses due to unspecific binding and requiring a minimum of three adjacent peptides with a relevant signal.

This article is protected by copyright. All rights reserved. 
Positive binding was defined individually for each immunoglobulin subclass as follows based on recognition patterns and signal intensity of the array:

Three consecutive peptides exceeding the median plus four times the MAD in any individual in the allergic and/or sensitized group but negative in the control group was used to define IgE-binding peptides on known HDM allergens.

Five consecutive peptides above the $95^{\text {th }}$ percentile in any of the patients in any of the three groups (allergic, sensitized non-allergic and non-sensitized non-allergic) defined IgGrecognized peptides and 5 consecutive peptides above the $99^{\text {th }}$ percentile in any individual in any of the three groups defined IgG4-recognized peptides.

For the Der f genome-derived proteome sequences, where in contrast to the known allergens sequences only a 7-amino-acid overlap was possible, a different algorithm was applied. Two consecutive peptides exceeding the median plus four times the MAD in any of the patients in the allergic or sensitized group but negative in the control group were defined as positive for IgE. Two consecutive peptides above the $95^{\text {th }}$ percentile in any of the patients in any of the three groups was the cut-off for IgG and IgG4 positive peptides.

Due to the strong heterogeneity regarding epitope diversity (15) and binding patterns of allergic individuals, a peptide was considered positive if at least one patient exhibited a positive signal.

In the $172 \mathrm{~K}$ high-density peptide arrays, a positive signal was defined as one that exceeds the median plus four times the MAD from non-allergic, non-sensitized individuals. For every individual in the pAIT or placebo group, the change in positivity per peptide over the course of the treatment was analyzed. Some peptides exhibited de novo positivity and some peptides lost their positivity during the treatment.

This article is protected by copyright. All rights reserved. 
Normalization, data analysis and graphical illustration were conducted by R (https://www.rproject.org/; The R Foundation for Statistical Computing, Vienna, Austria), and GraphPad Prism (GraphPad Prism version 7, GraphPad Software, La Jolla, California, USA). Differences between the placebo and the treatment group were calculated using the MannWhitney-U test. For comparisons of allergen-specific IgE, IgG and IgG4 levels at the various time points (baseline, 12 and 24 months of treatment) in the respective groups, the Wilcoxonsigned-rank test was used. A p-value of $<0.05$ was assumed as statistically significant for all tests.

\section{RESULTS}

\section{Preventive allergen immunotherapy with HDM extract results in a significantly broader}

\section{IgG repertoire}

Plasma samples from the randomized double-blind placebo-controlled pAIT trial were evaluated for $\operatorname{IgE}, \operatorname{IgG}$ and $\mathrm{IgG} 4$ binding in a $172 \mathrm{~K}$ high-density, high-resolution peptide array, containing 16-mer peptides derived from all published HDM allergens (Der $\mathrm{f}$ and Der p) (Figure 1). At baseline, IgG diversity was well matched between placebo and pAIT. The diversity of IgG-binding peptides to HDM allergens was significantly higher in the pAIT after 2 years of treatment compared to the placebo. Allergen-specific IgG4 is considered crucial for blocking of the allergen-specific responses and one of the key protective mechanisms of AIT. There was mildly increased IgG4 diversity at baseline in the pAIT group $(\mathrm{p}=0.12)$, which was not significant. In line with allergen-specific IgG data, IgG4 epitope diversity was higher in the pAIT group after 24 months of treatment compared to the placebo-treated patients (Figure 2). There was no increase in IgE repertoire diversity to Der $\mathrm{p}$ and Der $\mathrm{f}$ allergens in case of pAIT. However, the placebo group displayed a trend towards 
an overall increase over time displaying significance 12 months post inclusion (Figure 2).

In addition, we analyzed the overlap in peptide recognition between $\operatorname{IgE}$ and $\operatorname{IgG}$ including IgG4. Preventive AIT-treated patients showed after $24 \mathrm{~m}$ months of treatment significantly more IgG specificity to pre-existing IgE HDM allergen epitopes mapped at baseline as compared to the placebo group (median 18 vs 40 overlapping epitopes, Figure E1).

\section{Epitope binding characteristics to the Der $f$ proteome}

The recently published genome of Der f (14) allowed us to perform a holistic approach covering the whole proteome of Der $\mathrm{f}$. This allowed for the investigation of yet undescribed binding sides (all proteins that exist in Der $\mathrm{f}$ with exception of the known Der $\mathrm{f}$ allergens), in particular, the dynamics of epitope recognition during pAIT. It also may act as a surrogate for a beneficial bystander suppression on binding of Der f-derived proteins that are underrepresented/not represented in the treatment extract.

Within the first 12 months of pAIT, a strong reduction of $\operatorname{IgE}$ binding was observed $(\mathrm{p}<0.01)$, whereas no significant changes in the placebo group occurred. Although the pattern of a slightly increased number of Der f recognized peptides by IgG was detected, comparable to the pattern observed for the HDM allergens, it did not reach significance $(p=0.12)$. No changes regarding Der f-specific IgG4 binding were observed (Figure 3).

\section{Individual allergen patterns reflect overall changes}

Allergen extracts used for AIT include a broad variety of allergens at different concentrations. Therefore, $\operatorname{IgE}, \operatorname{IgG}$ and $\operatorname{IgG} 4$ new peptide recognition frequencies were analyzed at the level of individual allergens. The extend of de novo generated epitopes per allergen was significantly higher with regards to $\operatorname{IgG}$ and significantly lower for $\operatorname{IgE}$ in the 
treatment group as compared to the placebo treated group. No significant differences were seen regarding delta of IgG4-recognized peptides (Figure 4). IgE diversity increased in the majority of individual allergens within 24 months at preschool age when placebo was applied $(\mathrm{p}<0.05)$. This epitope spreading was not observed in the pAIT group. IgG diversity increased significantly in the pAIT group during treatment $(\mathrm{p}<0.05)$ whereas no increase was observed in the placebo group. IgG4 diversity at a single allergen level demonstrated significant baseline differences and displayed no differences at the endpoint (after 2 years of treatment) (Figure E2).

\section{DISCUSSION}

AIT has been assumed to modify disease progression and there is good retrospective and some prospective evidence that AIT reduces de novo sensitizations to allergens. It may further affect subsequent events like the development of allergic asthma $(9,10,17,18)$. However, robust prospective data as well as mechanistic data at the molecular level supporting the beneficial effects of preventive interventions are scarce. This study provides first evidence of how sublingual pAIT beneficially impacts linear epitope diversity in preschool children before the onset of clinical symptoms.

In a previous publication that focused on the safety aspects of this trial (7), we were able to demonstrate a TGF-beta and IL10 dependent immunomodulatory effect at a T-cell level. Moreover, the generation of blocking IgG antibodies against Der p1 and Der p2 was demonstrated in a quantitative manner. These outcomes are well-known in therapeutic application of AIT. However, the changes at a molecular level with regards to epitope diversity remain unclear. Moreover, a key aspect of this project is to delineate dynamics of diversity.

This article is protected by copyright. All rights reserved. 
The longest preventive sublingual pAIT trial that was performed in very young children $(<12$ months) (6) could not show prevention of de novo sensitization to HDM in a high-risk population. But there was evidence that the co-sensitizations were significantly reduced in the treatment group. It is unclear whether the observed $\operatorname{IgE}$ responses in the treatment group will result in clinical symptoms or rather reflect $\operatorname{IgE}$ responses in a high-risk group upon exposure without direct clinical implications. Follow-up data will bring more information about regarding clinics.

It is known that one of the characteristics of the atopic march is the development of IgE antibodies to new epitopes and the spreading of sensitization to new allergenic proteins from other sources (19). Evidence for a linkage of epitope diversity and disease severity has also been provided for milk and peanut allergy (20-22). Therefore, we would expect an increase in IgE diversity over time in the placebo group reflecting the natural course in a high-risk group. In fact, we saw a significant increase in diversity in the placebo group within the first 12 months after inclusion. Interestingly, this progression was modified by pAIT. Although our study is not powered to analyze clinical outcomes, it is tempting to speculate that this difference could reflect a beneficial interference with the natural progression of allergic disease.

Another important finding is the significantly more prominent increase in HDM allergenspecific IgG diversity over time in the pAIT group. Again, this may represent a beneficial disease-modifying effect of pAIT at a molecular level. This finding adds to numerous quantitative observations highlighting the importance of $\operatorname{IgG}$ antibody production in the 
context of AIT. IgG antibodies are known to compete with IgE for epitopes and are, therefore, considered blocking antibodies (23, 24). However, amounts and diversity of antibodies are not necessarily linked (25). Both, abundance and diversity of blocking antibodies are most likely beneficial for the prevention of an allergic phenotype.

Despite its limitations by only mapping linear epitopes, high-density peptide arrays allow the assessment of antibody diversity to a much broader variety of peptides compared to other conventional techniques such as ELISA or bead-based approaches. Conformational epitope assessment would certainly be desirable, in particular when looking at environmental allergens. Currently, high throughput methodologies allowing for the assessment of conformational binding are not available. Several important HDM linear epitopes in major allergens such as Der p 1, Der p 2, Der f 2 and Der f 25 and others as Der p 10 and Der f 7, have been demonstrated to be important for IgE binding in HDM-sensitized patients (26-31).

Beyond a surrogate analysis including all known allergens we also investigated whether dynamics of epitope recognition are different when looking at HDM allergens individually. In fact, IgE diversity increased in the placebo group significantly in the majority of Der $\mathrm{p}$ and Der $f$ allergens whereas that did not happen in the pAIT-treated group. On the contrary, a statistically significant increase of $\operatorname{IgG}$ diversity was observed in the treatment group.

In addition to known allergens, we chose a new approach by synthesising the whole proteome of $\operatorname{Der} f$. The intention was to include still unknown linear epitopes from the HDM itself. This approach harbors the potential to identify new allergens on the one hand but more importantly allows for the assessment of potential bystander effects. As anticipated, the 
changes in the proteome-derived peptide pool were not as pronounced as in the allergen pool. Nevertheless, IgE binding was significantly reduced at 12 months of treatment and a trend towards an increase of IgG diversity was observed. This adds to the body of evidence discussed above and suggests a beneficial immunomodifying effect of pAIT.

Regarding the clinical effects of preventive AIT on asthma development, the recently published GAP trial on sublingual grass AIT in allergic rhinitis patients did not meet the primary endpoint. However, it provided evidence that AIT modifies grass pollen allergy by reducing asthma symptoms and medication scores with a more pronounced effect in the 2year follow-up period (32). Moreover, the increase in allergen-specific IgE was significantly lower in the treatment group. Interestingly, the younger the children were, the stronger the beneficial effect on the prevention of asthma symptoms (10). Patients in our study are even younger and represent an earlier stage of the disease. Although our study was not powered to assess clinical efficacy we checked whether there was any evidence suggestive for an impact of pAIT on asthma development over a longer period of time. Four-year follow-up data showed a lower asthma incidence (1/9 treatment vs 3/10 placebo; data not shown).

In conclusion, the use of high-density peptide arrays revealed that HDM pAIT in children 2-5 years of age shows molecular evidence for immunomodulation by influencing epitope recognition and therefore interfering in the natural course of atopic march. Therefore, this study contributes to a better understanding of pAIT mechanisms of action at a B cell level. Further research is desired and essential to evaluate and understand the secondary prevention of HDM allergy and asthma.

This article is protected by copyright. All rights reserved. 


\section{FIGURE LEGENDS}

\section{Fig. 1. Study design.}

Plasma samples from the randomized double-blind placebo-controlled preventive sublingual AIT trial were evaluated for $\operatorname{IgE}$, $\operatorname{IgG}$ and $\mathrm{IgG} 4$ binding in a 172k high-density peptide array, containing peptides derived from all published HDM allergens (Der $\mathrm{f}$ and Der $\mathrm{p}$ ) and the whole Der f proteome.

\section{Fig. 2. Time course of absolute number of recognized linear peptides from HDM allergens.}

Number of bound linear peptides from HDM allergens in the pAIT and placebo group at baseline, 12 and 24 months of treatment to $\operatorname{IgE}$ (pAIT $n=9$; placebo $n=10)(A), \operatorname{IgG}(p A I T$ $\mathrm{n}=9$; placebo $\mathrm{n}=10$ ) (B) and IgG4 antibodies (pAIT $\mathrm{n}=7$; placebo $\mathrm{n}=8$ ) (C). pAIT= preventive allergen immunotherapy group

Fig. 3. Time course of absolute number of recognized linear peptides from Der $f$ proteome.

Number of bound linear peptides from Der $\mathrm{f}$ proteome in the pAIT and placebo group at baseline, 12 and 24 months of treatment to $\operatorname{IgE}$ (pAIT $n=9$; placebo $n=10)(A), \operatorname{IgG}(p A I T$ $\mathrm{n}=9$; placebo $\mathrm{n}=10$ ) (B) and IgG4 antibodies (pAIT $\mathrm{n}=7$; placebo $\mathrm{n}=8)(\mathrm{C})$. pAIT= preventive allergen immunotherapy group

\section{Fig. 4. Dynamics of single HDM allergen peptide recognition.}

Number of new epitopes per HDM allergen per person for $\operatorname{IgE}(p A I T n=9$; placebo $n=10)$, $\operatorname{IgG}(\mathrm{pAIT} \mathrm{n}=9$; placebo $\mathrm{n}=10$ ) and $\operatorname{IgG} 4$ (pAIT $\mathrm{n}=7$; placebo $\mathrm{n}=8$ ) antibodies. pAIT= preventive allergen immunotherapy group 


\section{TABLES}

Table 1. Baseline characteristics, according to the study group.

\begin{tabular}{|l|l|l|}
\cline { 2 - 3 } \multicolumn{1}{l|}{} & pAIT & Placebo \\
\hline $\mathrm{n}$ & 9 & 10 \\
\hline Age (median in years) & 4.01 & 3.60 \\
\hline Gender (f/m) & $2 / 7$ & $3 / 7$ \\
\hline Allergy Family History (pos/neg) & $5 / 4$ & $6 / 4$ \\
\hline HDM allergy after treatment & $1 / 9$ & $3 / 10$ \\
\hline
\end{tabular}

\section{REFERENCES}

1. Dhami S, Kakourou A, Asamoah F, Agache I, Lau S, Jutel M, et al. Allergen immunotherapy for allergic asthma: A systematic review and meta-analysis. Allergy 2017.

2. Peters RL, Neeland MR, Allen KJ. Primary Prevention of Food Allergy. Curr Allergy Asthma Rep 2017;17(8):52.

3. Muraro A, Halken S, Arshad SH, Beyer K, Dubois AE, Du Toit G, et al. EAACI food allergy and anaphylaxis guidelines. Primary prevention of food allergy. Allergy 2014;69(5):590-601.

4. Du Toit G, Sayre PH, Roberts G, Sever ML, Lawson K, Bahnson HT, et al. Effect of Avoidance on Peanut Allergy after Early Peanut Consumption. $N$ Engl $J$ Med 2016;374(15):1435-1443.

5. Novembre E, Galli E, Landi F, Caffarelli C, Pifferi M, De Marco E, et al. Coseasonal sublingual immunotherapy reduces the development of asthma in children with allergic

This article is protected by copyright. All rights reserved. 
rhinoconjunctivitis. J Allergy Clin Immunol 2004;114(4):851-857.

6. Zolkipli Z, Roberts G, Cornelius V, Clayton B, Pearson S, Michaelis L, et al. Randomized controlled trial of primary prevention of atopy using house dust mite allergen oral immunotherapy in early childhood. J Allergy Clin Immunol 2015;136(6):15411547.e1541-1511.

7. Szepfalusi Z, Bannert C, Ronceray L, Mayer E, Hassler M, Wissmann E, et al. Preventive sublingual immunotherapy in preschool children: first evidence for safety and protolerogenic effects. Pediatr Allergy Immunol 2014;25(8):788-795.

8. Demoly P, Kleine-Tebbe J, Rehm D. Clinical benefits of treatment with SQ house dust mite sublingual tablet in house dust mite allergic rhinitis. Allergy 2017;72(10):15761578

9. Marogna M, Tomassetti D, Bernasconi A, Colombo F, Massolo A, Businco AD, et al. Preventive effects of sublingual immunotherapy in childhood: an open randomized controlled study. Ann Allergy Asthma Immunol 2008;101(2):206-211.

10. Purello-D'Ambrosio F, Gangemi S, Merendino RA, Isola S, Puccinelli P, Parmiani S, et al. Prevention of new sensitizations in monosensitized subjects submitted to specific immunotherapy or not. A retrospective study. Clin Exp Allergy 2001;31(8):1295-1302.

11. Di Bona D, Plaia A, Leto-Barone MS, La Piana S, Macchia L, Di Lorenzo G. Efficacy of allergen immunotherapy in reducing the likelihood of developing new allergen sensitizations: a systematic review. Allergy 2017;72(5):691-704.

12. Kristiansen M, Dhami S, Netuveli G, Halken S, Muraro A, Roberts G, et al. Allergen immunotherapy for the prevention of allergy: A systematic review and meta-analysis. Pediatr Allergy Immunol 2017;28(1):18-29.

13. Posa D, Perna S, Resch Y, Lupinek C, Panetta V, Hofmaier S, et al. Evolution and predictive value of $\mathrm{IgE}$ responses toward a comprehensive panel of house dust mite allergens 
during the first 2 decades of life. J Allergy Clin Immunol 2017;139(2):541-549.e548.

14. Chan TF, Ji KM, Yim AK, Liu XY, Zhou JW, Li RQ, et al. The draft genome, transcriptome, and microbiome of Dermatophagoides farinae reveal a broad spectrum of dust mite allergens. J Allergy Clin Immunol 2015;135(2):539-548.

15. Hansen CS, Dufva M, Bogh KL, Sullivan E, Patel J, Eiwegger T, et al. Linear epitope mapping of peanut allergens demonstrates individualized and persistent antibody-binding patterns. J Allergy Clin Immunol 2016;138(6):1728-1730.

16. Christiansen A, Kringelum JV, Hansen CS, Bogh KL, Sullivan E, Patel J, et al. Highthroughput sequencing enhanced phage display enables the identification of patient-specific epitope motifs in serum. Sci Rep 2015;5:12913.

17. Roberts G, Pfaar O, Akdis CA, Ansotegui IJ, Durham SR, Gerth van Wijk R, et al. EAACI Guidelines on Allergen Immunotherapy: Allergic rhinoconjunctivitis. Allergy 2018;73(4):765-798.

18. Jacobsen L, Niggemann B, Dreborg S, Ferdousi HA, Halken S, Host A, et al. Specific immunotherapy has long-term preventive effect of seasonal and perennial asthma: 10-year follow-up on the PAT study. Allergy 2007;62(8):943-948.

19. Gould HJ, Sutton BJ. IgE in allergy and asthma today. Nat Rev Immunol 2008;8(3):205-217.

20. Shreffler WG, Beyer K, Chu TH, Burks AW, Sampson HA. Microarray immunoassay: association of clinical history, in vitro $\operatorname{IgE}$ function, and heterogeneity of allergenic peanut epitopes. J Allergy Clin Immunol 2004;113(4):776-782.

21. Flinterman AE, Knol EF, Lencer DA, Bardina L, den Hartog Jager CF, Lin J, et al. Peanut epitopes for IgE and IgG4 in peanut-sensitized children in relation to severity of peanut allergy. J Allergy Clin Immunol 2008;121(3):737-743.e710.

22. Lin J, Bruni FM, Fu Z, Maloney J, Bardina L, Boner AL, et al. A bioinformatics 
approach to identify patients with symptomatic peanut allergy using peptide microarray immunoassay. J Allergy Clin Immunol 2012;129(5):1321-1328.e1325.

23. Chen KW, Focke-Tejkl M, Blatt K, Kneidinger M, Gieras A, Dall'Antonia F, et al. Carrier-bound nonallergenic Der p 2 peptides induce IgG antibodies blocking allergeninduced basophil activation in allergic patients. Allergy 2012;67(5):609-621.

24. Aalberse $\mathrm{R}$. The role of $\mathrm{IgG}$ antibodies in allergy and immunotherapy. Allergy 2011;66 Suppl 95:28-30.

25. Vickery BP, Lin J, Kulis M, Fu Z, Steele PH, Jones SM, et al. Peanut oral immunotherapy modifies IgE and IgG4 responses to major peanut allergens. J Allergy Clin Immunol 2013;131(1):128-134.e121-123.

26. Jeannin P, Didierlaurent A, Gras-Masse H, Elass AA, Delneste Y, Cardot E, et al. Specific histamine release capacity of peptides selected from the modelized Der $\mathrm{p}$ I protein, a major allergen of Dermatophagoides pteronyssinus. Mol Immunol 1992;29(6):739-749.

27. Cui Y. Immunoglobulin E-binding epitopes of mite allergens: from characterization to immunotherapy. Clin Rev Allergy Immunol 2014;47(3):344-353.

28. Dai YC, Chuang WJ, Chua KY, Shieh CC, Wang JY. Epitope mapping and structural analysis of the anti-Der p 1 monoclonal antibody: insight into therapeutic potential. $J \mathrm{Mol}$ Med (Berl) 2011;89(7):701-712.

29. Zhong ZM, Zheng CD, Wang F. [Identification of the IgE-binding epitopes in main dust mite allergen Der p 1]. Nan Fang Yi Ke Da Xие Xие Bao 2011;31(7):1183-1186.

30. Asturias JA, Arilla MC, Gomez-Bayon N, Martinez A, Martinez J, Palacios R. Sequencing and high level expression in Escherichia coli of the tropomyosin allergen (Der $p$ 10) from Dermatophagoides pteronyssinus. Biochim Biophys Acta 1998;1397(1):27-30.

31. Li X, Yang HW, Chen H, Wu J, Liu Y, Wei JF. In Silico Prediction of T and B Cell Epitopes of Der f 25 in Dermatophagoides farinae. Int J Genomics 2014;2014:483905.

This article is protected by copyright. All rights reserved. 
32. Valovirta E, Petersen TH, Piotrowska T, Laursen MK, Andersen JS, Sorensen HF, et al. Results from the 5-year SQ grass SLIT-tablet asthma prevention (GAP) trial in children with grass pollen allergy. J Allergy Clin Immunol 2017.

Conflict of interest statement: All authors declare that they do not have any conflict of interest regarding this publication.

This article is protected by copyright. All rights reserved. 


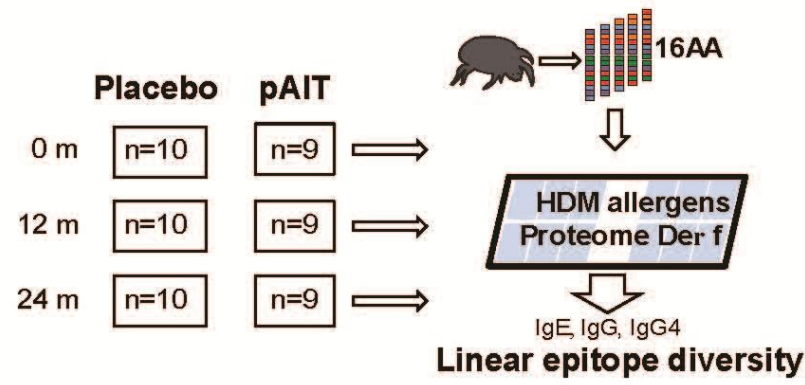

Figure 1

This article is protected by copyright. All rights reserved. 


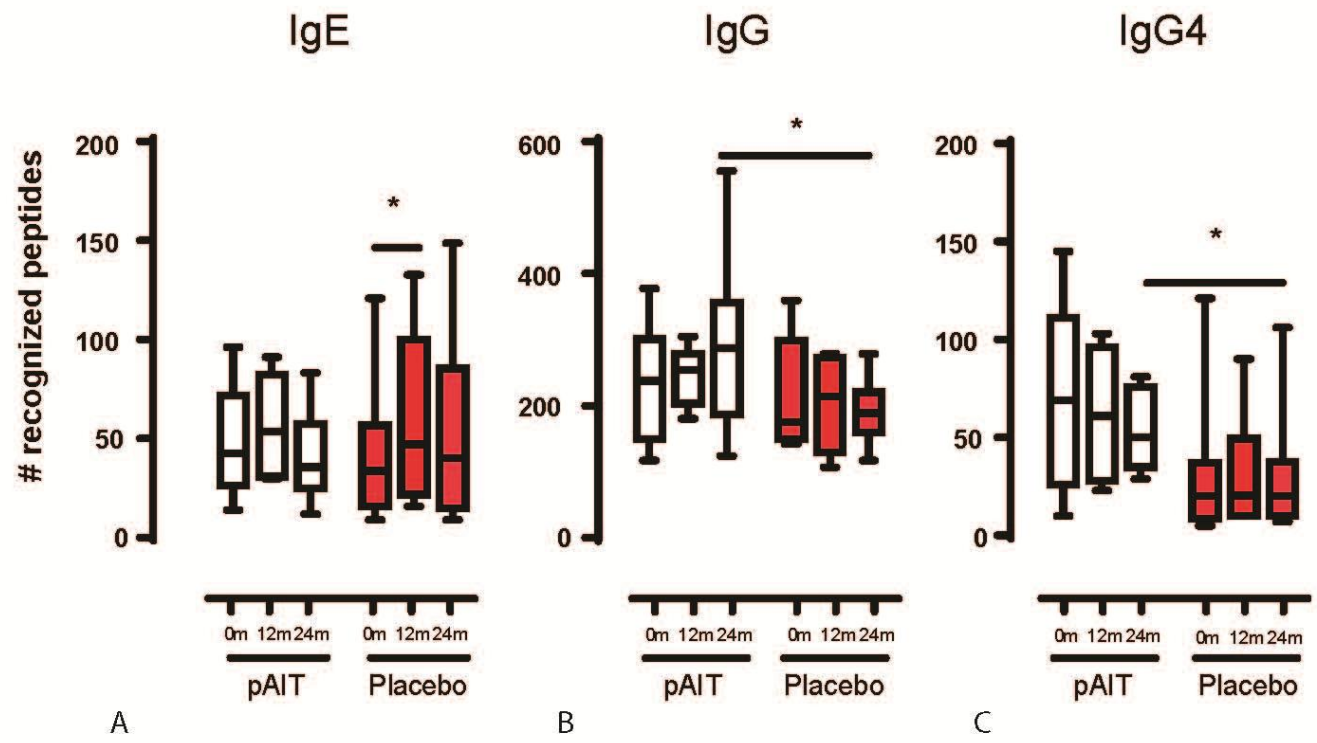

Figure 2

This article is protected by copyright. All rights reserved. 


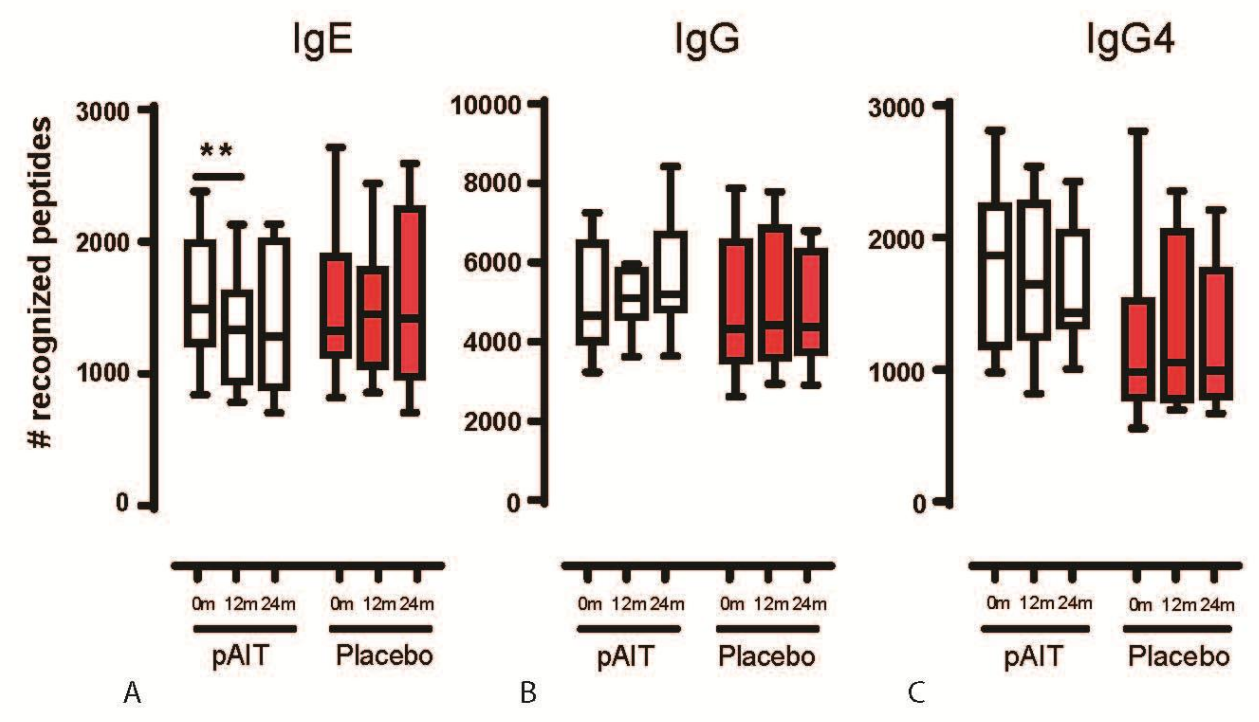

Figure 3

This article is protected by copyright. All rights reserved. 


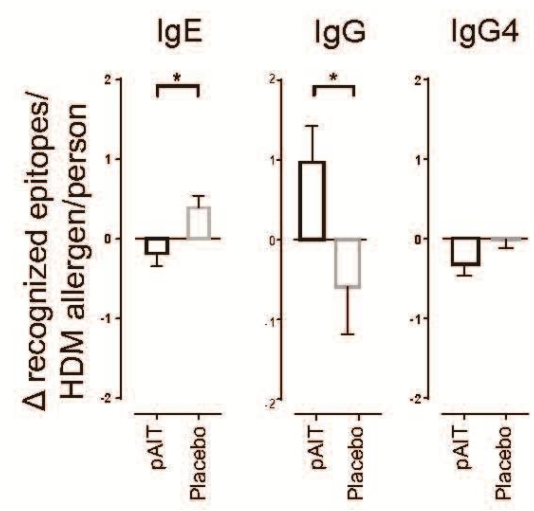

Figure 4

This article is protected by copyright. All rights reserved. 